\title{
Athletes and Supplements: Prevalence and Perspectives
}

\author{
Ina Garthe \\ The Norwegian Olympic and Paralympic Committee and Confederation of Sport
}

\author{
Ronald J. Maughan \\ St Andrews University
}

\begin{abstract}
In elite sport, where opponents are evenly matched, small factors can determine the outcome of sporting contests. Not all athletes know the value of making wise nutrition choices, but anything that might give a competitive edge, including dietary supplements, can seem attractive. Between $40 \%$ and $100 \%$ of athletes typically use supplements, depending on the type of sport, level of competition, and the definition of supplements. However, unless the athlete has a nutrient deficiency, supplementation may not improve performance and may have a detrimental effect on both performance and health. Dietary supplements are classified as a subcategory of food, so manufacturers are not required to provide evidence of product safety and efficacy, nor obtain approval from regulatory bodies before marketing supplements. This creates the potential for health risks, and serious adverse effects have been reported from the use of some dietary supplements. Athletes who compete in sports under an anti-doping code must also realize that supplement use exposes them to a risk of ingesting banned substances or precursors of prohibited substances. Government systems of regulations do not include specific laboratory testing for banned substances according to the WADA list, so a separate regulatory framework to evaluate supplements for their risk of provoking a failed doping test is needed. In the highperformance culture typical of elite sport, athletes may use supplements regardless of possible risks. A discussion around medical, physiological, cultural, and ethical questions may be warranted to ensure that the athlete has the information needed to make an informed choice.
\end{abstract}

Keywords: dietary supplements, elite athletes, ergogenic aids, banned substances

Many athletes, at all levels of competition, place great emphasis on the use of dietary supplements, but of all the factors that determine athletic performance, supplements can play only a very small role. Compared with factors such as talent, training, tactics, and motivation, nutrition has a small effect on performance, and supplements can be no more than a minor part of the athlete's nutrition strategy. Sporting competitions are generally designed so that individuals and teams are fairly evenly-matched: one-sided competition gives little satisfaction to either participants or spectators. Competitors are therefore anxious to seek even the smallest advantage. At the highest levels of competition, all of the participants will be genetically gifted, all will have trained intensively, and all will be highly motivated. Where the margins between success and defeat are small, the small factors can become the ones that determine the outcome of sporting contests. This perhaps explains why athletes are constantly searching for any opportunity to gain an advantage over their competitors. Lack of awareness of basic nutrition principles also leaves many athletes and nonathletes alike open to persuasion by the advertisements of those who profit from the sale of dietary supplements. When looking at the use of supplements by elite athletes, it is important to bear in mind that sports supplements are a relatively small part of a multi-billiondollar industry that depends primarily on fitness enthusiasts for

Garthe is with The Norwegian Olympic and Paralympic Committee and Confederation of Sport, Oslo, Norway. Maughan is with the School of Medicine, St Andrews University, St Andrews, United Kingdom. Address author correspondence to Ina Garthe at Ina.garthe@olympiatoppen.no. sales. Elite athletes, and those aspiring to elite status, comprise only a small part of the customer base.

\section{Definitions and Categorizations}

Sports supplements have been defined and categorized in many ways, but none of these definitions and classifications are entirely satisfactory. In general, categories include sports foods (gels, bars, drinks, protein powders), vitamins and minerals, herbals and botanicals, and ergogenic supplements (Table 1). In addition, there is a category which includes supplements for weight loss, products for increased libido, and there are also gluten-free, lactose-free, allergen-free, and functional foods, which may also be defined as food. The herbs and botanicals, functional foods, and super foods segments, which can be defined as foods, food ingredients, or supplements, are particularly difficult to study and define, due to the multiple, complex compounds and the heterogeneous content of biologically-active ingredients. Nevertheless, this category has developed fast in the last decades, driven in part by the common perception that natural equals healthy (Silano et al., 2011). However, in contrast to this naïve perception, some natural substances pose a serious health threat for consumers and some may cause a failed doping test. These findings support the need for stricter regulation, for better enforcement of existing regulations, and for greater awareness among consumers (Avelar-Escobar et al., 2012).

Because there is no clear boundary between dietary supplement and foods, the field is complex to navigate. Different definitions and categorizations of supplements obviously make it difficult to compare studies, and some of the differences between published studies 
Table 1 Categorization of Supplements by Use

\begin{tabular}{|c|c|c|}
\hline Category by Use & Examples & Comments: Risk-Assessments \\
\hline $\begin{array}{l}\text { Sports foods: Specialized products } \\
\text { used to provide a practical source of } \\
\text { nutrients when it is impractical to } \\
\text { consume everyday foods }\end{array}$ & $\begin{array}{l}\text { Sports drink, sports gel, liquid meal, } \\
\text { sports confectionery, sports bar }\end{array}$ & $\begin{array}{l}\text { Most sports foods, but not all, are low risk for contamination with } \\
\text { prohibited substances. }\end{array}$ \\
\hline $\begin{array}{l}\text { Medical supplements: Used to treat } \\
\text { clinical issues, including diagnosed } \\
\text { nutrient deficiencies }\end{array}$ & $\begin{array}{l}\text { Iron, calcium, multivitamin/mineral, } \\
\text { vitamin } D \text {, probiotics (gut/immune) }\end{array}$ & $\begin{array}{l}\text { Most—but not all—vitamin and mineral supplements purchased at } \\
\text { a pharmacy are produced with a strict pharmaceutical control. }\end{array}$ \\
\hline $\begin{array}{l}\text { Ergogenic supplements: Supplements } \\
\text { intended to enhance performance }\end{array}$ & $\begin{array}{l}\text { Caffeine, } \beta \text {-alanine, bicarbonate, nitrate } \\
\text { (beetroot juice), creatine }\end{array}$ & $\begin{array}{l}\text { Ergogenic supplements that are not on the World Anti-Doping } \\
\text { Agency (WADA) prohibited list are concentrates of substances } \\
\text { found in food. There is a risk of cross-contamination with pro- } \\
\text { hibited or harmful substances and of deliberate adulteration by the } \\
\text { addition of pharmaceutical agents. }\end{array}$ \\
\hline $\begin{array}{l}\text { Functional food and superfoods: } \\
\text { Purported to optimize health and } \\
\text { performance }\end{array}$ & $\begin{array}{l}\text { Herbs, seaweed, spirulina organic food, } \\
\text { plant fibers, seeds (chia seeds), natural } \\
\text { alkalizing fruits, raw juice and berry, } \\
\text { (acai, goji) extracts }\end{array}$ & $\begin{array}{l}\text { No guarantee of the amount of active biological substance. Product } \\
\text { heterogeneity makes it hard to identify and categorize biologically- } \\
\text { active ingredients. Herbal or traditional products, including animal } \\
\text { and plant materials, are found principally in Chinese, Korean, and/ } \\
\text { or herbal medicine prescriptions. Governmental regulation and } \\
\text { policies differ between countries. }\end{array}$ \\
\hline $\begin{array}{l}\text { Other supplements: Includes a wide } \\
\text { range of herbal and botanical extracts } \\
\text { and concentrates }\end{array}$ & $\begin{array}{l}\text { Supplements for: weight loss (shakes, } \\
\text { tablets), increased energy, increased } \\
\text { libido, prevention of hair loss }\end{array}$ & $\begin{array}{l}\text { May contain central nervous system stimulants (e.g., ephedrine) } \\
\text { and hormones or hormone precursors (e.g., norandrostenedione and } \\
\text { norandrostenediol). They are considered high risk for adulteration } \\
\text { due to the need for rapid and noticeable results by the consumer to } \\
\text { promote continued use of the product. To achieve these results, } \\
\text { potent pharmaceuticals are sometimes added by the manufacturers. }\end{array}$ \\
\hline
\end{tabular}

are simply due to different definitions. A recent meta-analysis on supplement use by athletes identified several challenges to the interpretation of the published evidence regarding the prevalence of supplement use within sport (Knapik et al., 2016). The major methodological challenges in the literature seem to be:

- Different definitions of supplements

- Diverse populations and level of performance

- Different methods of data collection

- Different timeframes

\section{Governmental Definitions}

The US Food and Drug Administration (FDA) has the following definition of supplements: "A dietary supplement is a product intended for ingestion that contains a 'dietary ingredient' intended to add further nutritional value to (supplement) the diet" (FDA, 2017). A "dietary ingredient" may be one, or any combination, of the following substances (in tablets, capsules, softgels, gelcaps, liquids, or powders):

- Vitamins

- Minerals

- Herbs or other botanicals

- Amino acids

- Dietary substances for use by people to supplement the diet by increasing the total dietary intake

- Concentrates, metabolites, constituents, or extracts

As dietary supplements are classified as a subcategory of food, manufacturers are not required to provide evidence of product safety and efficacy (Denham, 2017). While medications and drugs are governed by rigid pharmaceutical regulation, based on premarketing authorization and end-product control, dietary supplement manufacturers and distributors are not required to obtain approval from the FDA before marketing dietary supplements. This creates a substantial potential risk to the health of the public, and serious adverse effects have been reported from some dietary supplements that are currently being marketed (FDA, 2017).

Supplements are regulated on a national rather than global basis and regulations vary between countries. Before marketing a dietary supplement in the United States, the manufacturers are responsible for ensuring that the specific regulations are followed:

- The products it manufactures or distributes are safe

- Any claims made about the products are not false or misleading

- The products comply with the Federal Food, Drug, and Cosmetic Act and FDA regulations in all other respects

In Europe, the European Food Safety Authority (EFSA) has similar regulations and definitions on dietary supplements, and has established a framework for regulation of vitamin and mineral supplements to protect consumers against potential health risks and to ensure that they are not provided with misleading information (Directive 2002/46/EC, EFSA, 2017). They provide a list of vitamins and minerals that may be added for nutritional purposes, with specific upper and lower limits of vitamin and minerals (Directive 2002/46/EC, EFSA, 2017). With the level of resources required to control these marketing and safety regulations in this fast-growing segment, it is reasonable that the responsibility for committing to those regulations lies with the manufacturer. However, it can also create some challenges. In most countries, these regulations are enforced by periodic, but often infrequent, testing of random samples (Norwegian Food Safety Authority, 2017; FDA, 2017). Regulatory bodies must prove adulteration or misbranding or risk of illness/ injury before a dietary supplement can be removed from the market. This is time-consuming and requires substantial resources. 
According to marketing regulations in the United States, a dietary supplement cannot claim to diagnose, treat, cure, or prevent any disease. However, a study of 443 websites of 8 bestselling herbal products showed that $81 \%$ made one or more health claims; $55 \%$ claimed the product treated, prevented, diagnosed, or cured specific diseases; and $52 \%$ of those making claims omitted the federal disclaimer (Morris \& Avorn, 2003). In another study, 75\% of the most popular herbal supplements did not include on the label the key safety messages about warnings for medical conditions, drug interactions, and side effects (Raynor et al., 2011). Undoubtedly, stricter enforcement of the existing regulations that apply to manufacturers and distributors is needed, but, without the necessary resources to do tests and follow-up, the effect will continue to be limited.

The government systems of regulations and independent manufacturing quality programs do not include specific laboratory testing for banned substances according the World Anti-Doping Agency (WADA) list. A separate regulatory framework to evaluate supplements for their risk of provoking a failed doping test would be needed, but there is limited interest from the regulatory bodies, perhaps because this represents such a small part of the market.

\section{Motivations for Supplement Use}

There are several reasons why it is important to understand the athlete's motivation for supplements use, whereas one reason is to develop strategies for responsible supplement use. Another reason is to minimize the risk of excessive and harmful supplement use and to separate sports foods and medical supplements (used to treat clinical issues) from the use of ergogenic supplements that are intended specifically to enhance performance. There may be several different motivational factors for each category of supplements; food and supplements containing essential nutrients (e.g., vitamins) are mainly used for health reasons, with performance effects being secondary to better health, while ergogenic aids are used with the intention of maximizing performance. Further, athlete support staff may want to encourage a food-based approach to nutrition education, since the literature shows that most athletes can cover their nutrient needs through a varied diet, provided the energy intake is moderate to high (Thomas et al., 2016).

The final reason may be to identify the "gray zone", where athletes who use dietary supplements may be associated with an accepting attitude of doping at a later stage (the "gateway" theory, presented by Backhouse et al., 2013). There are some data to suggest that supplement users have more positive attitudes toward doping, and that they believe that doping is an effective way to increase performance (Backhouse et al., 2013). Others report that there seems to be an underlying cognitive component in the association between use of supplements and doping, and that use of supplements may influence reasoning patterns and the motivational incentive in favor of using prohibited substances at a later stage, even among adolescent athletes (Barkoukis et al., 2015). According to the literature, the prevalence of doping is higher in supplement users than in athletes who do not use supplements (Backhouse et al., 2013; Barkoukis et al., 2015). It is, however, important to note that these studies were not designed to identify a direct causality between supplement use and doping.

\section{Prevalence of Supplement Use}

Surveys regarding use of dietary supplements in the general population have consistently shown that supplements are used by a large part of the population, and this is substantiated by the sales figures of what is now a multi-billion-dollar global industry (Hämeen-Anttila et al., 2011; Timbo et al., 2006). According to national surveys of the general population in the United States, more than $40 \%$ of the adult population used dietary supplements in the period from 1988-1994, and this had increased to over one-half during 2003-2006 (Centers for Disease Control and Prevention, 2011). The Council for Responsible Nutrition (CRN), an industry-funded body, has an annual survey on dietary supplements, with a national sample of 2,007 adults aged $\sim 18$ years living in the United States. According to the most recent survey, $71 \%$ of US adults (more than 170 million people) report use of dietary supplements for the following reasons: "an overall health/ wellness benefit", "to get energy", and "to fill nutrient gaps in my diet" (CRN Consumer Survey on Dietary Supplements, 2016). That is an increase from 2015, where $68 \%$ reported intake of dietary supplements (CRN Consumer Survey on Dietary Supplements, 2015). The most used supplements were vitamin and mineral products. Supplement users aged 18-34 years reported in 2015 that they anticipated their supplement use to increase over the next 5 years. Data from the 2016 survey suggest that this projection is likely to be realized, as young adults are increasing their use of dietary supplements.

Use of dietary supplements within athletic populations is reported to be relatively high in most studies (Baylis et al., 2001; Heikkinen et al., 2002; Kim et al., 2011; Lun et al., 2012) (Table 2). This agrees with the study by Sobal and Marquart (1994), who undertook a comprehensive analysis of published studies of supplement use among collegiate athletes and elite athletes. A total of 10,274 athletes, males and females, were included in this meta-analysis, which showed that $46 \%$ of college athletes and $59 \%$ of elite athletes used dietary supplements (Sobal \& Marquart, 1994).

As mentioned above, the review and meta-analysis by Knapik et al. (2016) highlighted some of the challenges when comparing data from different studies due to different methods of data collection. For example, Lun et al. (2012) reported a supplementation use of $81-100 \%$ in a sample of 440 Canadian elite athletes, of whom $76 \%$ were competing at the international level. They found an association between total weekly training hours and supplement use, with an increasing prevalence from $67 \%$ for $<5$ weekly training hours to $95 \%$ for those training $>25 \mathrm{hr} /$ week. Not surprisingly, the most used supplements were sports supplements, which are often recommended by professional support staff for use in relation to training and competitions.

The association between supplement use and training load, found by Lun et al. (2012), agrees with the review by Knapik et al. (2016) and with more recent reports by Erdman et al. (2006) and Heikkinen et al. (2002), who concluded that elite athletes used more supplements than nonelite athletes, and that sports supplements were the supplement used most commonly. Further, several studies show that athletes from endurance-based sports use supplements to a greater extent than athletes from other sport categories (Erdman et al., 2006; Heikkinen et al., 2002; Lun et al., 2012; Shaw et al., 2016).

An alternative way of assessing the prevalence of supplement use is by analysis of declaration forms completed by athletes who are selected for doping control. In these settings, the athletes are asked to declare any prescription or nonprescription medication, vitamins, food supplements, herbal products, and any other substance they have taken within the past 7 days. Table 2 shows that athletes declare the use of a wide range of different supplements, 


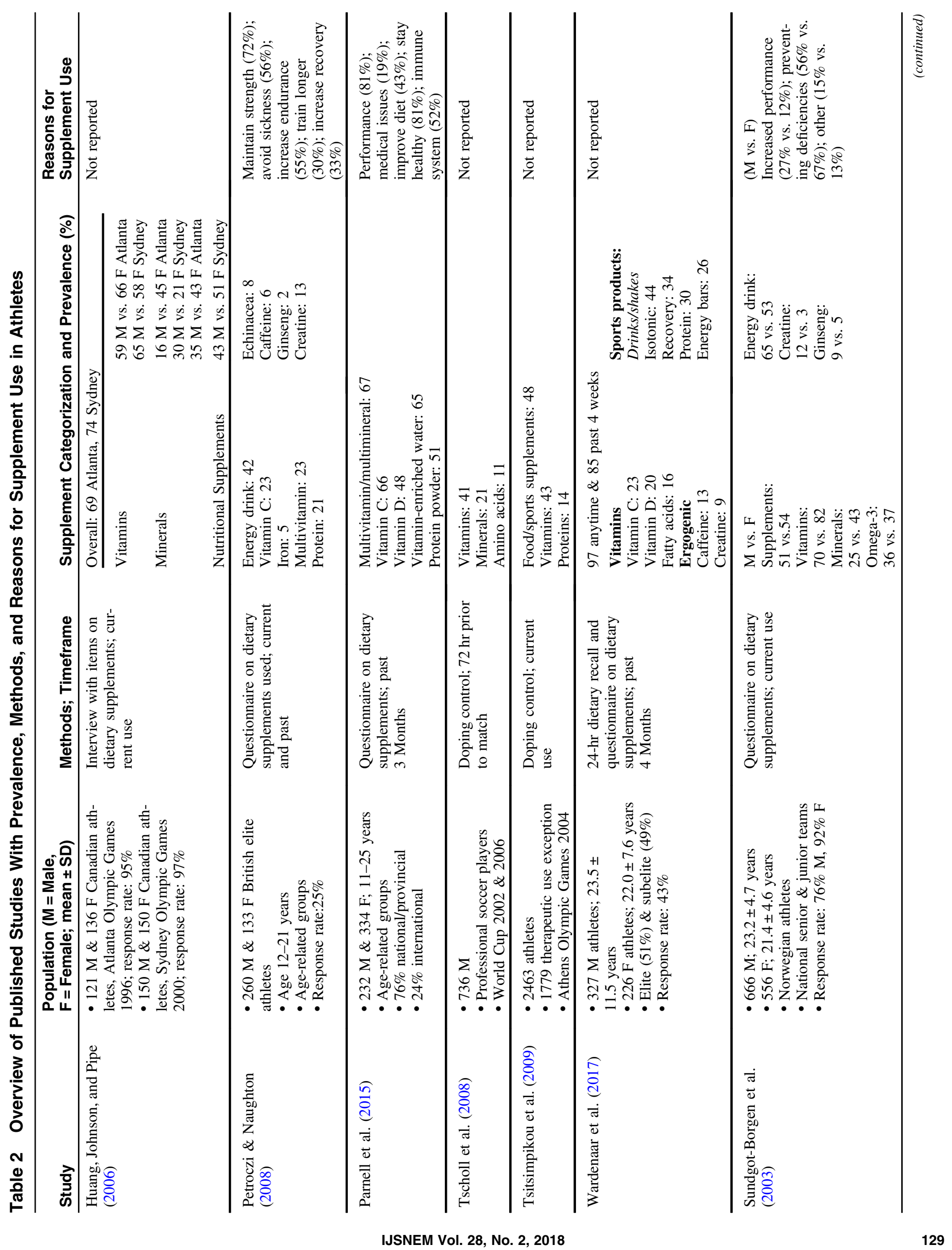




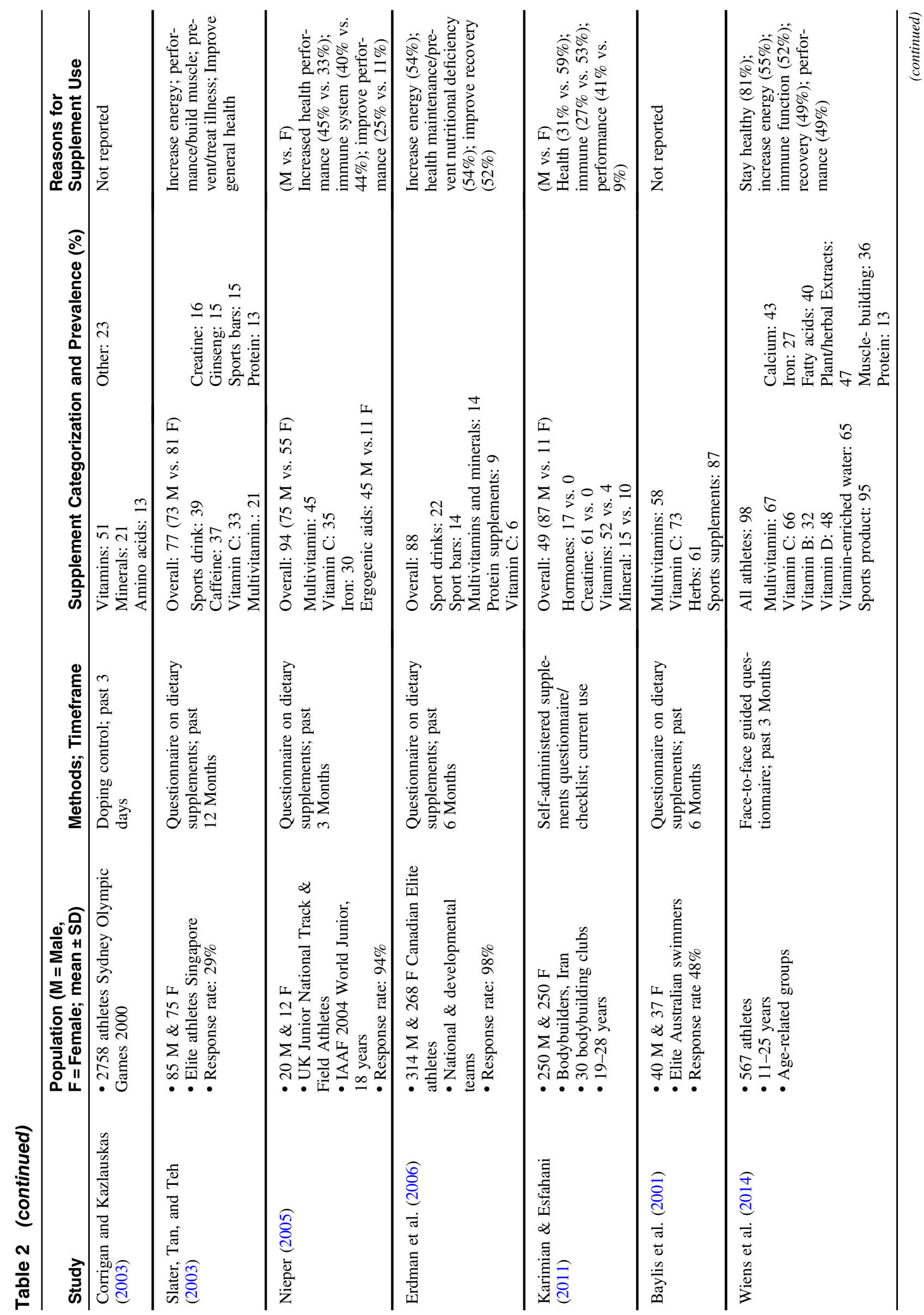




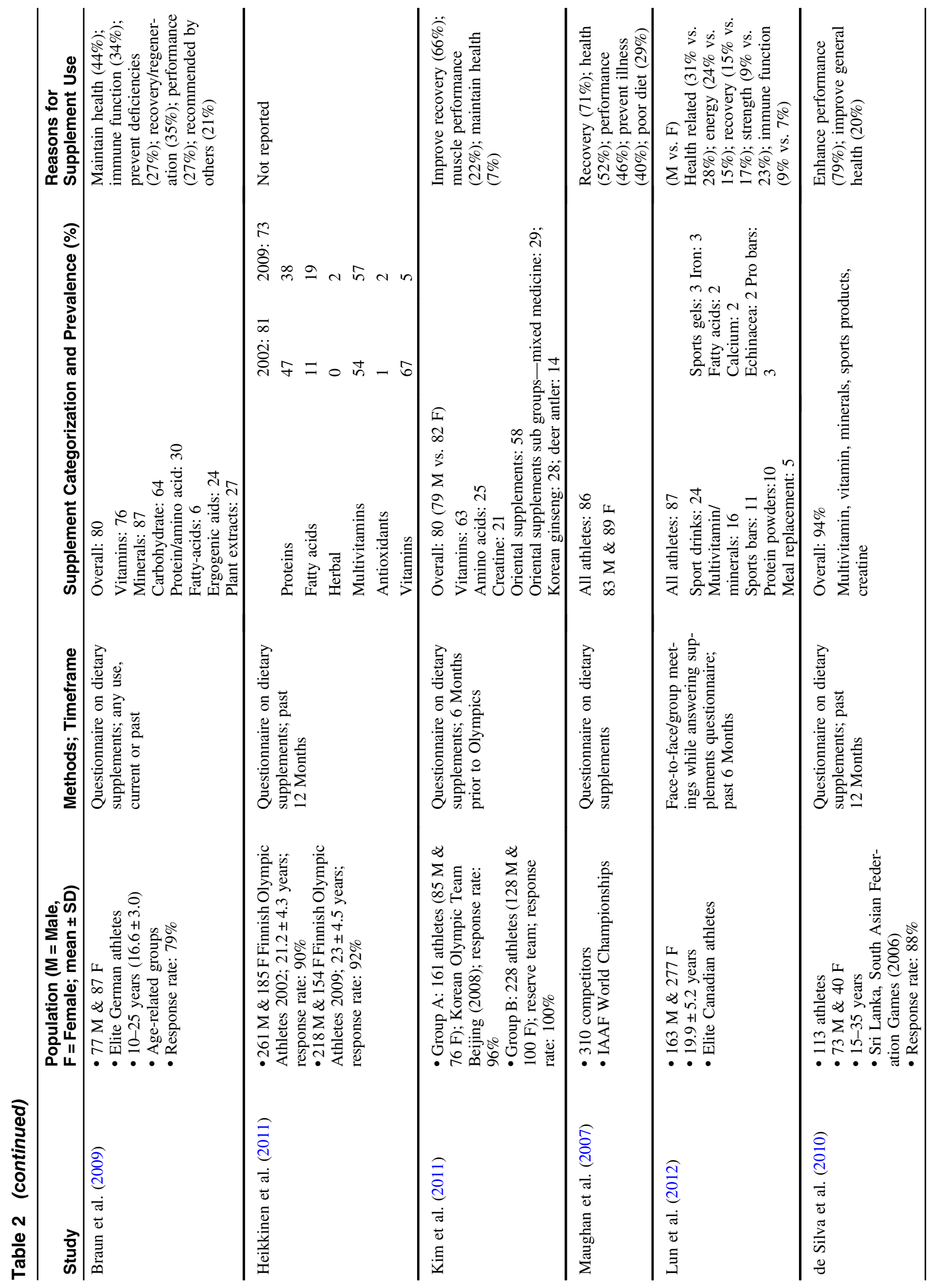


with vitamins and proteins/amino acids being the most widely-used supplements (Corrigan \& Kazlauskas, 2003; Tscholl et al., 2010; Tsitsimpikou et al., 2009).

These data should, however, be interpreted with caution. Some athletes (especially younger athletes) may experience doping controls as stressful and/or consider dietary supplements as less important information in these settings; also, the declaration of substances is limited to a 7-days timeframe prior to testing. Furthermore, most studies use self-reporting data via questionnaires or declaration reports and can be a valuable source of information only if the athletes report truthfully. Athletes may forget to declare supplements that they have been taking, or they may be aware that contaminated supplements may cause an adverse finding and may therefore be tempted to declare a wide range of products "just in case".

\section{Prevalence and Sex}

Sobal and Marquart (1994) found a higher use of dietary supplement in female athletes (57\%) than in male athletes (47\%). Nieper (2005) investigated the use of nutritional supplements in a small sample of 32 national track and field athletes competing at the World Junior Championships 2004, and found that $62 \%$ of the athletes reported use of supplements, with a trend toward a higher use in female athletes $(75 \%)$ than in males (55\%) (Table 2). In contrast to this, however, Karimian and Esfahani (2011) examined supplement use in 250 male and 250 female bodybuilders in Iran; supplement use was reported by $87 \%$ of the males but by only $11 \%$ of the females. Further, several studies did not find any difference between sexes (Kim et al., 2013; Sundgot-Borgen et al., 2003; Wiens et al., 2014). Wiens et al. (2014) reported no overall sexrelated difference in use of supplement per se, but they found that male athletes were more likely to consume protein powder and ergogenic supplements, typically associated with increased muscle mass, whereas female athletes were most likely to consume vitamin and mineral supplements, typically associated with increased health. Although more sex-specific studies in elite athletes are needed, it is tempting to conclude that sex-specific use of supplements seems to be related to the type of supplements (e.g., creatine vs. vitamins) and to the character and culture of the sports (endurance vs. aesthetic).

\section{Prevalence and Age}

The use of supplements seems to be endemic in the athletic population, and there is evidence that supplement use begins at an early age. Among 164 young (aged 10-25 years) German elite athletes, the prevalence of dietary supplement use was estimated to be $80 \%$ (Braun et al., 2009). This is markedly higher than data of the German National Nutrition Survey II, which showed that 16$19 \%$ of all German adolescents (aged 14-18 years) reported using dietary supplements (Federal Research Center for Nutrition and Food, 2008). Braun et al. (2009) reported that the use of supplements differed between the age categories and level of performance: athletes $>18$ years competing at the international level reported higher use $(100 \%)$ than younger athletes competing at the national or regional level. Several studies show the same pattern of supplement use among young athletes, where prevalence, type, and number of supplements used increase with increasing age and training hours/load (Corrigan \& Kazlauskas, 2003; Dietz et al., 2014; Parnell et al., 2015; Pedrinelli et al., 2015; Petroczi \& Naughton, 2008; Tscholl et al., 2008).

Maughan et al. (2007) recommended that athletes $<18$ years of age not engage in supplement use, except where medically indicted (e.g., iron-deficiency), but the evidence suggests that this is not the prevailing attitude in health teams and medical personnel or among parents and coaches surrounding the athlete. Figure 1 suggests how a progressive nutrition strategy might be developed for young athletes.

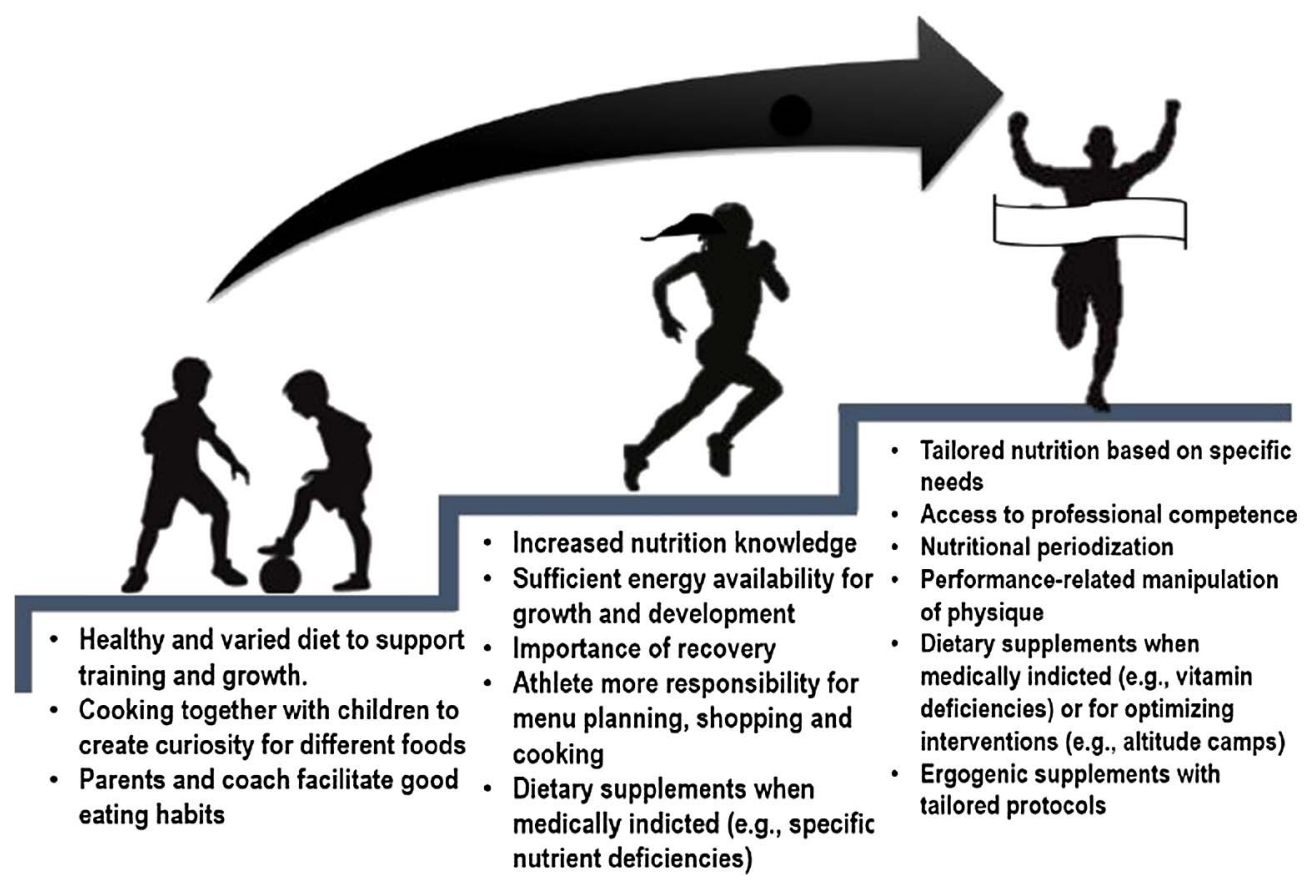

Figure 1 - Stages in the athletic, educational, and nutrition development of the young athlete. 


\section{Table 3 Situations Where Athletes Should Consider Using Dietary Supplements}

Where specific nutrient deficiencies have been identified by appropriate investigations
Where the consequences of chronic inadequate energy intake have been established, including menstrual dysfunction and low bone mineral density
During periods of weight loss or in those following diets that exclude a group of nutrients (e.g., vegans)
Where specific foods are excluded from the diet because of allergies and food intolerance
Prior to different interventions to optimize adaptations (e.g., altitude training camps and iron status)
When traveling to places with limited variety of foods, with unfamiliar foods, or with issues relating to food hygiene or food safety

To conclude, the prevalence of athletes using supplements varies greatly between surveys, with a range of reported use from $40-100 \%$, indicating that use is widespread in athletic populations. Sports supplements, vitamin and mineral supplements, and herbs (dependent on country of origin) are generally the most used supplements.

\section{Potential Benefits of Supplement Use in Athletes}

The use of supplements in sport tends to be viewed in negative terms, with a focus on reducing prevalence and protecting the athlete from using supplements that may cause a positive doping test or may be harmful to health. However, supplements may be important in some stages in life or for some athletes with nutritional challenges, such as the athlete who is vegan or who has a specific medical condition. The governments in many Nordic countries have official guidelines regarding specific supplements, such as daily intake of omega-3 fatty acids and vitamin D (Nordic Nutrition Recommendations, 2014). Others permit the fortification of specific foods with essential nutrients (iron, calcium, B vitamins, etc.). When it comes to the athletic population, the official guidelines still apply (Wardenaar et al., 2017), and there may be other situations where athletes would benefit from supplements (Table 3 ). In these circumstances, it may be beneficial to use a carefully-designed program of supplementation to optimize health and performance.

\section{Pattern and Reasoning for Use}

Users cite various reasons for consuming dietary supplements, though they are often very different from the specific uses identified above. These reasons are more often based on unfounded beliefs than on any understanding of the issues at stake. Dietary supplements may not be promoted for the prevention or treatment of illness, but it is obvious that many consumers use them for this purpose. Sport-specific reasons for supplement use include a belief that the stress of intense training/competition cannot be met by food alone, and that supplements can offer a specific advantage in either training or competition. There is also an awareness that successful competitors are using supplements, and the use of supplements is often endorsed or encouraged by influential individuals in the athlete's circle, including coaches, parents, and fellow athletes.

In the general population, consumption of nutritional supplements is often driven by a belief that they confer health benefits above and beyond those that can be achieved by eating normal foods (Reinert et al., 2007). Among athletes and physically active individuals, there are several additional issues related specifically to the physical and mental aspects of exercise performance. Of course, athletes are also concerned to stay healthy as neither effective training nor successful competition is possible if health is compromised. Illness or injury that requires periods of time out from training can disrupt preparations, and illness at the time of key competitions can ruin an athlete's competitive season. Supplements that promise to enhance recovery, whether from illness, injury, or training, are obviously popular with athletes, and they often use a combination of products (Baylis et al., 2001; Heikkinen et al., 2002).

Reasons for using supplements among 310 competitors at the IAAF World Championships were: to aid recovery from training (71\%), for health (52\%), to improve performance (46\%), to prevent or treat an illness (40\%), and to compensate for a poor diet $(29 \%)$ (Maughan et al., 2007). Corrigan and Kazlauskas (2003) found that $51 \%$ of the 2,758 athletes selected for doping control at the Sydney Olympic Games of 2000 reported the use of vitamin supplements for the following reasons/statements: (a) vitamins enhance performance; (b) athletes have greater requirements than the sedentary population; (c) fear that others who take them could have a competitive edge; (d) if one is good, 10 or more must be better; (e) vitamins are needed to overcome stress; (f) vitamins are lost in the sweat during exercise; and $(\mathrm{g})$ turnover of vitamins is increased during exercise (Corrigan \& Kazlauskas, 2003) (Table 2).

The available information does not provide a complete picture of the athletes' intentions and rationale relating to supplement use. When comparing their reasons for supplement use with the products that they report consuming, there seems to be a mismatch, especially in younger athletes (Baylis et al., 2001; de Silva et al., 2010; Parnell et al., 2015; Trakman et al., 2016; Wiens et al., 2014). For example, athletes reported using multivitamins to increase athletic performance or vitamin water to gain strength and power.

A summary of the most commonly cited reasons for supplement use is given in Figure 4.

\section{Informed Choices}

Some athletes use supplements on an "ad hoc basis", unaware of what the active ingredient(s) are or of the amount of those ingredients. Consuming multiple supplements may increase the risk of exposure to harmful levels of specific substances or interactions causing adverse health outcomes (e.g., calcium and interference of iron uptake) (Baylis et al., 2001; de Silva et al., 2010; Parnell et al., 2015; Trakman et al., 2016; Wiens et al., 2014). The indiscriminate use of supplements is a cause for concern and demands educational interventions at an early age for athletes, coaches, and parents/family members.

There is some evidence-largely anecdotal, but supported by some evidence from surveys - that the quantity of supplements used by athletes often exceeds the recommended amount. This "more is better" philosophy is encouraged by the belief that rivals are using even higher doses. Even elite athletes may not have access to professional advice that might counter some of these beliefs. Heikkinen et al. (2011) reported that only 27\% of the 372 


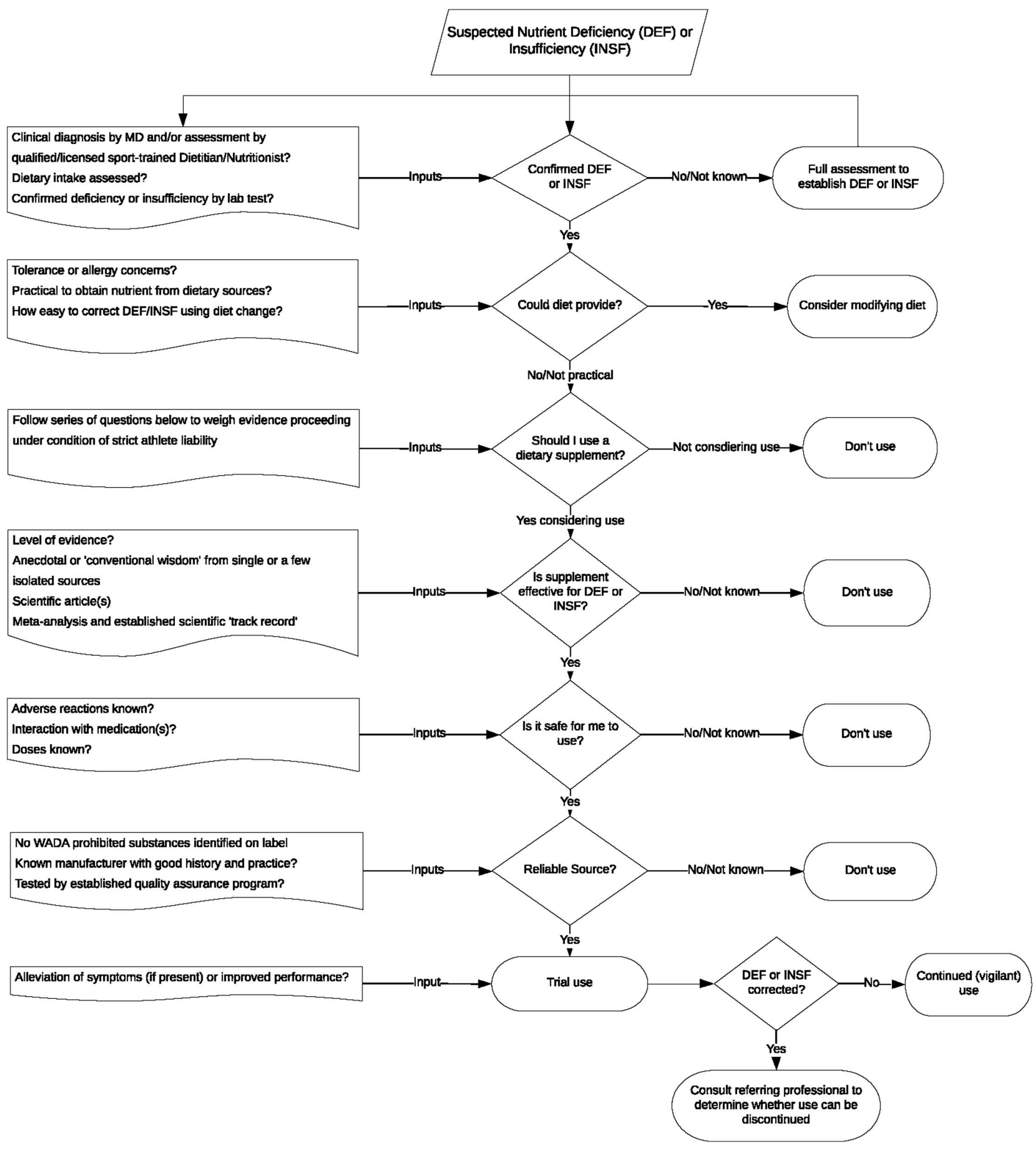

Figure 2 - Flow chart to guide informed decision making and reducing risk of anti-doping rule violation during nutritional supplement use.

elite Finnish athletes surveyed in 2009 had an opportunity to consult a sports nutrition professional. Even when these opportunities are available, not all athletes choose to make use of them, preferring instead to get their nutrition advice from sources that they may see as being more congenial. Nieper (2005) showed similar results in the 32 national track and field athletes, where $72 \%$ of the athletes had access to a sports dietician but chose not to use that resource. Coaches $(65 \%)$ had the greatest influence on 

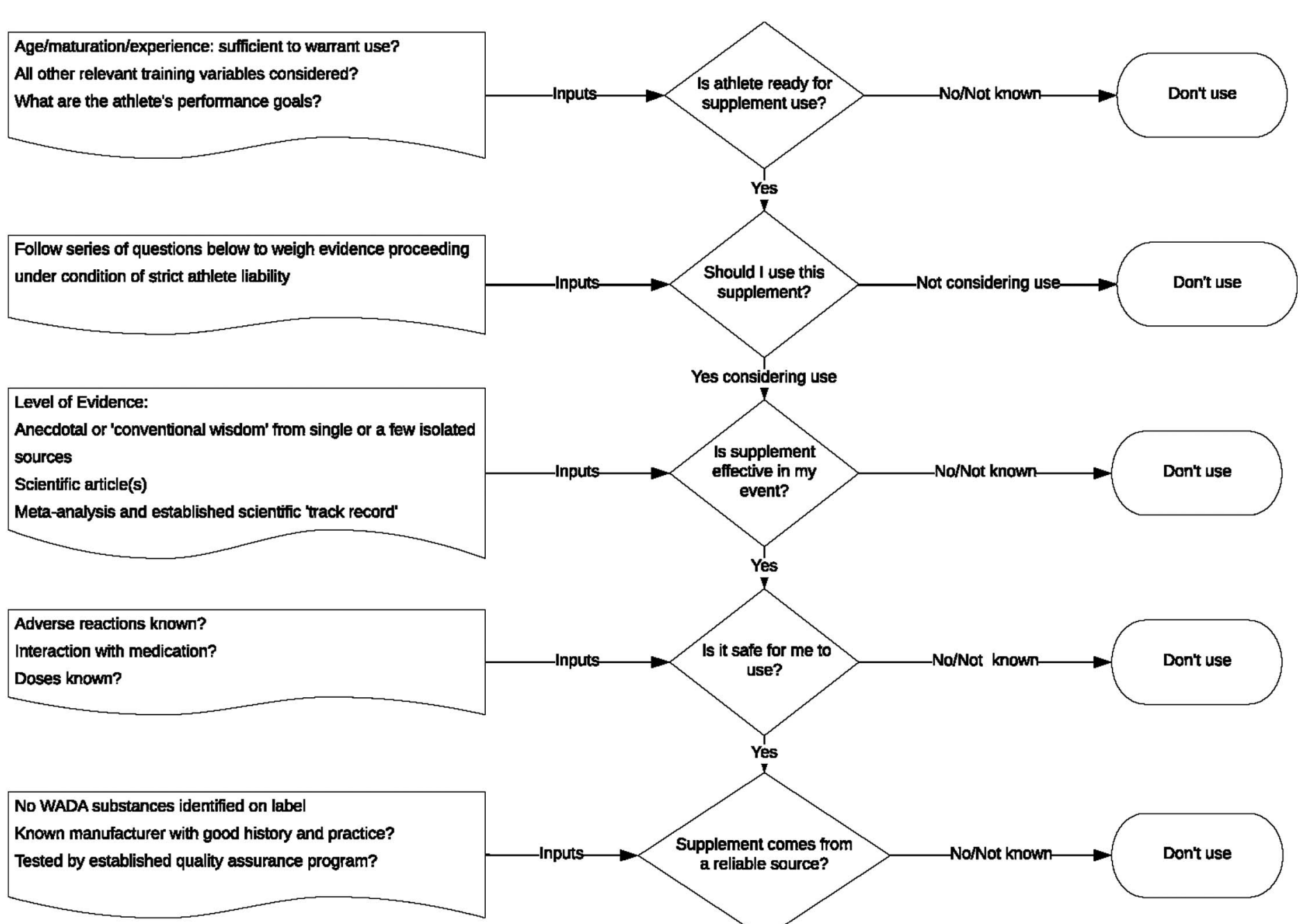

Trial in practice and/or less important competition
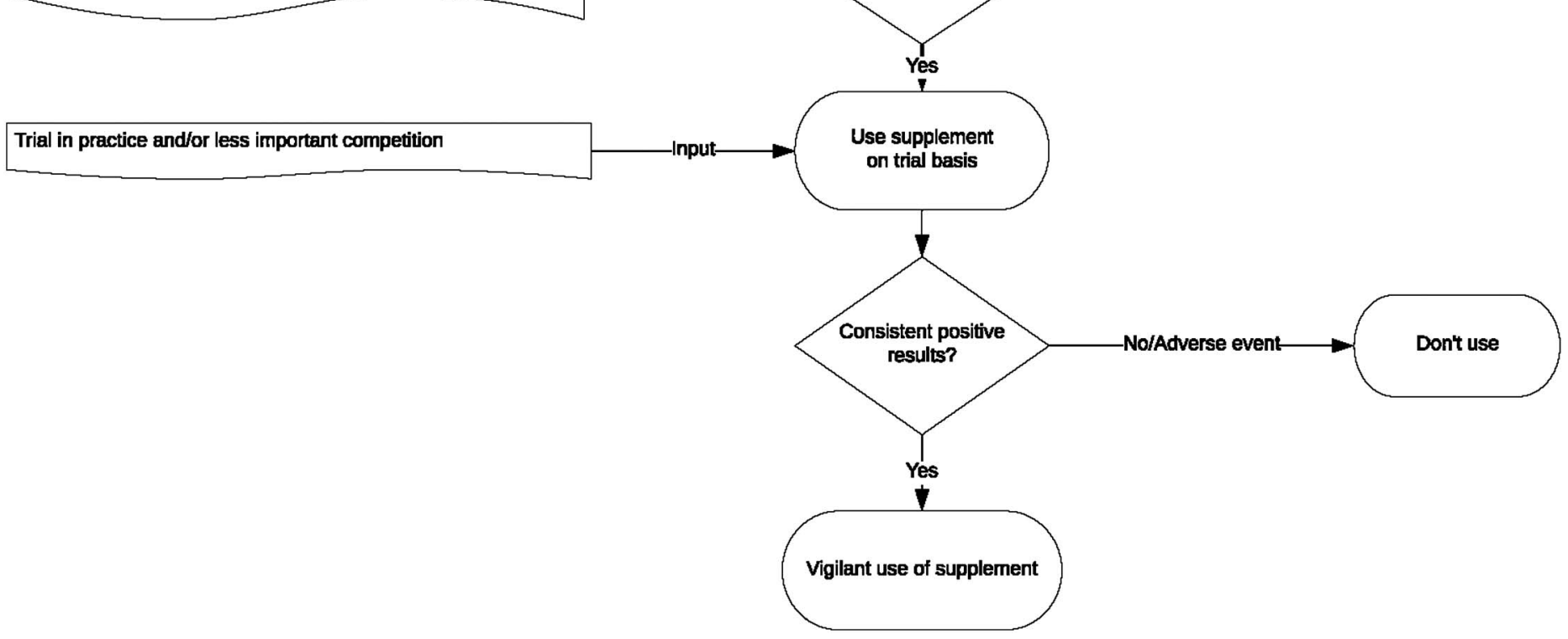

Figure 3 - Flow chart to guide informed decision making and reducing risk of anti-doping rule violation during ergogenic supplement use.

supplementation practices, with doctors $(25 \%)$ and sports dieticians $(30 \%)$ being less important (Nieper, 2005). This agrees with the study from Wiens et al. (2014), where they reported that the main sources of information were family/friends (74\%), coaches (44\%), athletic trainers (40\%), medical doctors (33\%), and, in a lower place than the others, sport nutritionists (32\%), which is similar to the findings of other studies (Braun et al., 2009; Kim et al., 2011).

According to the literature, it seems that most athletes get dietary advice from coaches, fellow athletes, and other important 


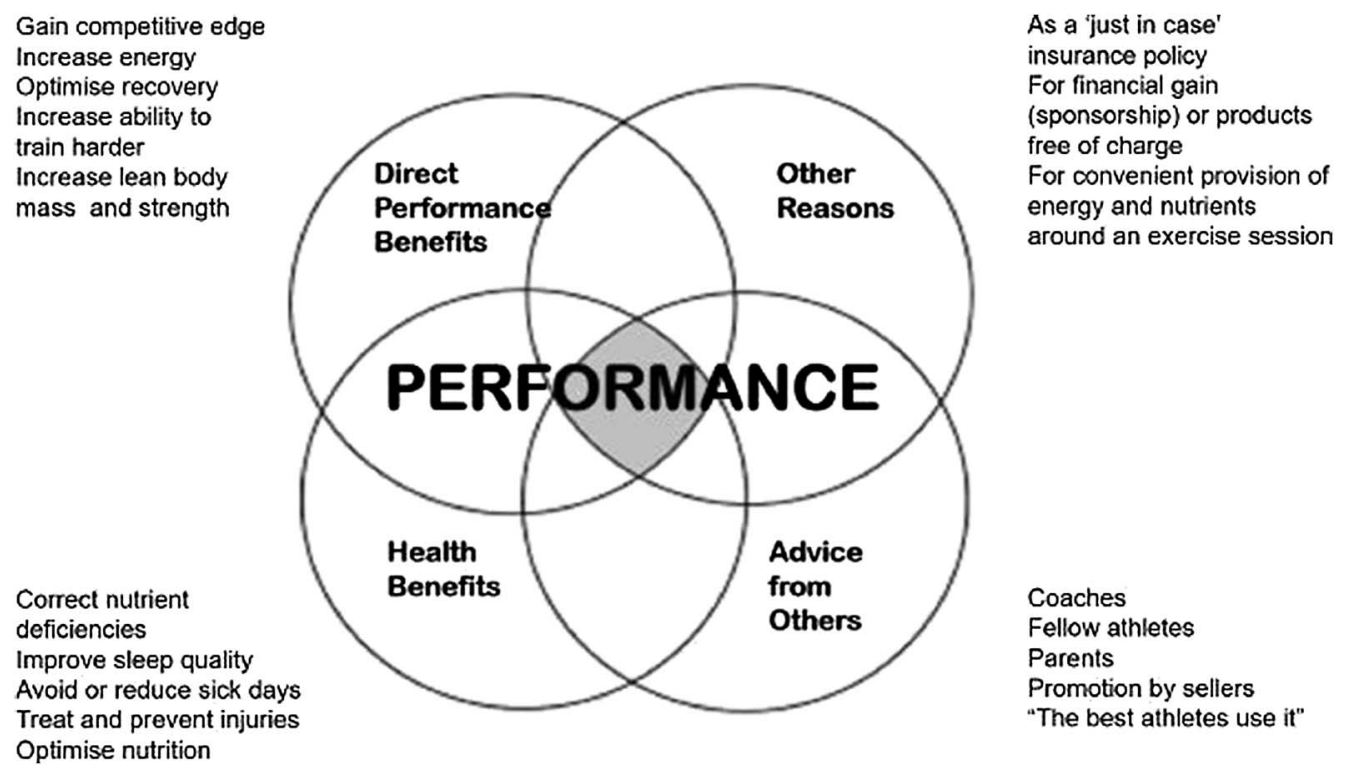

Figure 4 - Common reasons given by athletes for the use of supplements.

persons such as family and friends (Denham, 2017; Heikkinen et al., 2011; Nieper, 2005; Sundgot-Borgen et al., 2003). Athletes who have access to a sports dietitian may choose not to use that opportunity for various reasons. Lovell et al. (2013) observed that athletes' efficacy expectations of a female sports dietitian and their willingness to work with them are influenced by the dietitians' physical appearance: nonobese dietitians were ranked and rated more positively by the athletes in terms of their preference to work with them and their perceived effectiveness than dietitians classified as obese. Athletes who perceive a dietitian to be overweight may also conclude that they have limited competence in sports nutrition, although that may not be the case. Support staff must fully appreciate the sports-specific culture and physiological demands of the sport and must also accept that most elite athletes are highly driven by performance, with a sometimes extreme focus on performance rather than on health. If the athlete and dietitian cannot engage at the same level of communication and experience, it might be difficult to build the trust and alliances that are essential for a "hands-on" practitioner.

A recent study from the Netherlands evaluated the effect of dietary counseling on supplement use and found that athletes who had counseling used more supplements than those who did not (Wardenaar et al., 2017). The study found that the increased use was mainly due to an increased use of vitamin supplements, mirroring the recommendations the athletes got during counseling. This suggests that information from a counselor may have a positive influence, but limitations in the study design limit the conclusions that can be drawn from this study.

Marik and Flemmer (2012) suggested that the belief that supplements can confer health and performance benefits for the average consumer may be erroneous. They concluded that "with the possible exceptions of Vitamin D and omega-3 fatty acids there is no data to support the widespread use of dietary supplements in Westernized populations; indeed, many of these supplements may be harmful" (p. 161). Though the quality of the evidence on which these conclusions were based was often poor, and the analysis of the evidence lacked rigor, this review does raise legitimate concerns regarding the widespread assumption that supplement use confers health benefits on the consumer and that it is free from any risk of adverse health outcomes. This supports the view of Rock (2007), who reported that individuals who use dietary supplements generally report above-average dietary nutrient intakes and healthier diets. Nieper's study of national track and field athletes, showed that $83 \%$ of the athletes who did not use supplements believed they could be harmful, compared to only $42 \%$ of those who used supplements (Nieper, 2005). Further, athletes who used supplements were also more likely to believe that exercise increases the need for supplements (83\% compared to 18\%; Nieper, 2005). Unless an athlete has a nutrient deficiency, supplementation is unlikely to improve health or performance and can in fact have a detrimental effect on both performance, via blunted training adaptation (Paulsen et al., 2014), and on health, via increased risk of injuries and toxicity (García-Cortés et al., 2016). In addition, athletes who compete in sports under an anti-doping code must realize that supplement use exposes them to a risk of a positive doping test (Maughan, 2013). Thus, there are several factors and questions to consider if an athlete wants to use supplement:

1. Is there a scientific rationale for a potential positive effect on health and/or performance?

2. Is it possible that the supplement can have an adverse effect on health and/or performance?

3. Does the athlete need it?

4. Is it safe in the long-term?

If the supplement passes the questions, the practitioner has to make sure that the supplements are used appropriately. Sometimes athletes want to use supplements regardless of available information and recommendations. In these cases, the practitioner should ensure that the athlete has the information needed to make an informed choice, as the final responsibility rests with the athlete. A suggested flowchart related to use and evaluation of supplements is presented in Figures 2 and 3.

\section{Summary and Practical Implications}

Many athletes place great emphasis on the use of dietary supplements, but it is important to recognize that, of all the factors that 
determine athletic performance, supplements have only a very small role. Knowing that supplement use exposes them to a risk of ingesting banned substances or precursors of prohibited substances, a cost-benefit analysis should be part of any discussion about supplement use. Working with elite athletes involves being a part of a high-performance culture where performances are measured by results, and every small improvement counts. If basic ethical guidelines regarding supplements and doping are not part of the culture or are not clearly communicated, athletes may feel encouraged to take high-risk decisions to prioritize performance. A discussion around medical, physiological, cultural, and ethical questions may be warranted, to ensure that the athlete has the information needed to make an informed choice.

\section{Acknowledgments}

The authors would like to thank all the athletes who have contributed with time and openness related to use of dietary supplements. The authors thank those who contributed to the development of Figures 2 and 3. RJM and IG have equally contributed to the writing process. The authors have no conflict of interest to disclose.

\section{References}

Avelar-Escobar, G., Mendez-Navarro, J., Ortiz-Olvera, N., Castellanos, G., Ramos, R., Gallardo-Cabrera, V.E., . . . Dehesa-Violante, M. (2012). Hepatotoxicity associated with dietary energy supplements: Use and abuse by young athletes. Annals of Hepatology, 11(4), 564-569. PubMed

Backhouse, S.H., Whitaker, L., \& Petróczi, A. (2013). Gateway to doping? Supplement use in the context of preferred competitive situations, doping attitude, beliefs, and norms. Scandinavian Journal of Medicine \& Science in Sports, 23(2), 244-252. PubMed doi:10.1111/ j.1600-0838.2011.01374.x

Barkoukis, V., Lazuras, L., Lucidi, F., \& Tsorbatzoudis, H. (2015). Nutritional supplement and doping use in sport: Possible underlying social cognitive processes. Scandinavian Journal of Medicine \& Science in Sports, 25(6), e582-e588. PubMed doi:10.1111/sms.12377

Baylis, A., Cameron-Smith, D., \& Burke, L.M. (2001). Inadvertent doping through supplement use by athletes: Assessment and management of the risk in Australia. International Journal of Sport Nutrition and Exercise Metabolism, 11(3), 365-383. PubMed doi:10.1123/ijsnem. 11.3.365

Braun, H., Koehler, K., Geyer, H., Kleiner, J., Mester, J., \& Schanzer, W. (2009). Dietary supplement use among elite young German athletes. International Journal of Sport Nutrition and Exercise Metabolism, 19(1), 97-109. PubMed doi:10.1123/ijsnem.19.1.97

Centers for Disease Control and Prevention. (2011). Retrieved from https://www.cdc.gov/nchs/data/hus/hus 11.pdf

Corrigan, B., \& Kazlauskas, R. (2003). Medication use in athletes selected for doping control at the Sydney Olympics. Clinical Journal of Sport Medicine, 13(1), 33-40. PubMed doi:10.1097/00042752200301000-00007

CRN Consumer Survey on Dietary Supplements. (2015). Retrieved from https://www.crnusa.org/CRNconsumersurvey/2015/

CRN Consumer Survey on Dietary Supplements. (2016). https://www. crnusa.org/resources/crn-2016-annual-survey-dietary-supplements

Denham, B.E. (2017). Athlete information sources about dietary supplements: A review of extant research. International Journal of Sport Nutrition and Exercise Metabolism, 27(4), 325-334. PubMed doi: 10.1123/ijsnem.2017-0050 de Silva, A., Samarasinghe, Y., Senanayake, D., \& Lanerolle, P. (2010). Dietary supplement intake in national-level Sri Lankan athletes. International Journal of Sport Nutrition and Exercise Metabolism, 20(1), 15-20. PubMed doi:10.1123/ijsnem.20.1.15

Dietz, P., Ulrich, R., Niess, A., Best, R., Simon, P., \& Striegel, H. (2014). Prediction profiles for nutritional supplement use among young German elite athletes. International Journal of Sport Nutrition and Exercise Metabolism, 24(6), 623-631. PubMed doi:10.1123/ijsnem. 2014-0009

Erdman, K.A., Fung, T.S., \& Reimer, R.A. (2006). Influence of performance level on dietary supplementation in elite Canadian athletes. Medicine \& Science in Sports \& Exercise, 38(2), 349-356. PubMed doi:10.1249/01.mss.0000187332.92169.e0

European Food Safety Authority. (2017). Retrieved from http://ec.europa. eu/dgs/health_food-safety/index_en.htm

Federal Research Center for Nutrition and Food. (2008). Retrieved from http://ernaehrungsdenkwerkstatt.de/fileadmin/user_upload/EDWT ext/ TextElemente/NVS/NVSII_Basis_ZweiTeil_270508_Druck.pdf

García-Cortés, M., Robles-Díaz, M., Ortega-Alonso, A., Medina-Caliz, I., \& Andrade, R.J. (2016). Hepatotoxicity by dietary supplements: A tabular listing and clinical characteristics. International Journal of Molecular Sciences, 17(4), 537. PubMed doi:10.3390/ijms17040537

Hämeen-Anttila, K.P., Niskala, U.R., Siponen, S.M., \& Ahonen, R.S. (2011). The use of complementary and alternative medicine products in preceding two days among Finnish parents - a population survey. BMC Complementary and Alternative Medicine, 11, 107. PubMed doi:10.1186/1472-6882-11-107

Heikkinen, A., Alaranta, A., Helenius, I., \& Vasankari, T. (2002). Use of dietary supplements in Olympic athletes is decreasing: A follow-up study between 2002 and 2009. Journal of the International Society of Sports Nutrition, 8(1), 1. PubMed doi:10.1186/1550-2783-8-1

Heikkinen, A., Alaranta, A., Helenius, I., \& Vasankari, T. (2011). Dietary supplementation habits and perceptions of supplement use among elite Finnish athletes. International Journal of Sport Nutrition and Exercise Metabolism, 21(4), 271-279. PubMed doi:10.1123/ijsnem. 21.4.271

Huang, S.H., Johnson, K., \& Pipe, A.L. (2006). The use of dietary supplements and medications by Canadian athletes at the Atlanta and Sydney Olympic Games. Clinical Journal of Sport Medicine, 16(1), 27-33.

Karimian, J., \& Esfahani, P.S. (2011). Supplement consumption in body builder athletes. Research in Medical Sciences, 16(10), 1347-1353. PubMed

Kim, J., Kang, S.K., Jung, H.S., Chun, Y.S., Trilk, J., \& Jung, S.H. (2011). Dietary supplementation patterns of Korean Olympic athletes participating in the Beijing 2008 summer Olympic games. International Journal of Sport Nutrition and Exercise Metabolism, 21(2), 166-174. PubMed doi:10.1123/ijsnem.21.2.166

Kim, J., Lee, N., Lee, J., Jung, S.S., Kang, S.K., \& Yoon, J.D. (2013). Dietary supplementation of high-performance Korean and Japanese judoists. International Journal of Sport Nutrition and Exercise Metabolism, 23(2), 119-127. PubMed doi:10.1123/ijsnem.23.2.119

Knapik, J.J., Steelman, R.A., Hoedebecke, S.S., Austin, K.G., Farina, E.K., \& Lieberman, H.R. (2016). Prevalence of dietary supplement use by athletes: Systematic review and meta-analysis. Sports Medicine, 46(1), 103-123. PubMed doi:10.1007/s40279-015-0387-7

Lovell, G.P., Parker, J.K., \& Slater, G.J. (2013). Influence of female sports dietitians' physical characteristics on athlete perception of effectiveness. International Journal of Sport Nutrition and Exercise Metabolism, 23(3), 282-286. PubMed doi:10.1123/ijsnem.23.3.282

Lun, V., Erdman, K.A., Fung, T.S., \& Reimer, R.A. (2012). Dietary supplementation practices in Canadian high-performance athletes. 
International Journal of Sport Nutrition and Exercise Metabolism, 22(1), 31-37. PubMed doi:10.1123/ijsnem.22.1.31

Marik, P.E., \& Flemmer, M. (2012). Do dietary supplements have beneficial health effects in industrialized nations: What is the evidence? Journal of Parenteral and Enteral Nutrition, 36(2), 159-168. PubMed doi:10.1177/0148607111416485

Maughan, R.J. (2013). Quality assurance issues in the use of dietary supplements, with special reference to protein supplements. The Journal of Nutrition, 143(11), 1843S-1847S. PubMed doi:10. 3945/jn.113.176651

Maughan, R.J., Depiesse, F., \& Geyer, H. (2007). The use of dietary supplements by athletes. Journal of Sports Science, 25, S103-S113. PubMed doi:10.1080/02640410701607395

Morris, C.A., \& Avorn, J. (2003). Internet marketing of herbal products. The Journal of the American Medical Association, 290, 1505-1509. PubMed doi:10.1001/jama.290.11.1505

Nieper, A. (2005). Nutritional supplement practices in UK junior national track and field athletes. The British Journal of Sports Medicine, 39(9), 645-649. PubMed doi:10.1136/bjsm.2004.015842

Nordic Council of Ministers. (2014). Integrating nutrition and physical activity 2012 (5th ed.). Copenhagen, Denmark: Author.

Norwegian Food Safety Authority. (2017). Food supplements. Retrieved from https://www.mattilsynet.no/language/english/food_and_water/ food_supplements/food_supplements.16383

Parnell, J.A., Wiens, K., \& Erdman, K.A. (2015). Evaluation of congruence among dietary supplement use and motivation for supplementation in young, Canadian athletes. Journal of the International Society of Sports Nutrition, 12, 49. PubMed doi:10.1186/s12970015-0110-y

Paulsen, G., Hamarsland, H., Cumming, K.T., Johansen, R.E., Hulmi, J.J., Børsheim, E., . . . Raastad, T. (2014). Vitamin C and E supplementation alters protein signalling after a strength training session, but not muscle growth during 10 weeks of training. The Journal of Physiology, 592(24), 5391-5408. PubMed doi:10.1113/jphysiol. 2014.279950

Pedrinelli, A., Ejnisman, L., Fagotti, L., Dvorak, J., \& Tscholl, P.M. (2015). Medications and nutritional supplements in athletes during the 2000, 2004, 2008, and 2012 FIFA futsal world cups. BioMed Research International, 870308. doi:10.1155/2015/870308

Petroczi, A., \& Naughton, D.P. (2008). The age-gender-status profile of high performing athletes in the UK taking nutritional supplements: Lessons for the future. Journal of the International Society of Sports Nutrition, 5, 2. PubMed doi:10.1186/1550-2783-5-2

Raynor, D.K., Dickinson, R., Knapp, P., Long, A.F., \& Nicolson, D.J. (2011). Buyer beware? Does the information provided with herbal products available over the counter enable safe use? BMC Medicine, 9, 94. PubMed doi:10.1186/1741-7015-9-94

Reinert, A., Rohrmann, S., Becker, N., \& Linseisen, J. (2007). Lifestyle and diet in people using dietary supplements: A German cohort study. The European Journal of Nutrition, 46(3), 165-173. PubMed doi: 10.1007/s00394-007-0650-2

Rock, C.L. (2007). Multivitamin-multimineral supplements: Who uses them? The American Journal of Clinical Nutrition, 85(1), 277S-279S. PubMed doi:10.1093/ajcn/85.1.277S

Shaw, G., Slater, G., \& Burke, L.M. (2016). Supplement use of elite Australian swimmers. International Journal of Sport Nutrition and
Exercise Metabolism, 26(3), 249-258. PubMed doi:10.1123/ijsnem. 2015-0182

Silano, V., Coppens, P., Larrañaga-Guetaria, A., Minghetti, P., \& RothEhrang, R. (2011). Regulations applicable to plant food supplements and related products in the European Union. Food \& Function, 2(12), 710-719. PubMed doi:10.1039/c1fo10105f

Slater, G., Tan, B., \& Teh, K.C. (2003). Dietary supplementation practices of Singaporean athletes. International Journal of Sport Nutrition and Exercise Metabolism, 13(3), 320-332.

Sobal, J., \& Marquart, L.F. (1994). Vitamin/mineral supplement use among athletes: A review of the literature. The International Journal of Sport Nutrition, 4(4), 320-334. PubMed doi:10.1123/ijsn. 4.4.320

Sundgot-Borgen, J., Berglund, B., \& Torstveit, M.K. (2003). Nutritional supplements in Norwegian elite athletes - impact of international ranking and advisors. Scandinavian Journal of Medicine \& Science in Sports, 13(2), 138-144. PubMed doi:10.1034/j.1600-0838.2003. 10288.x

Thomas, D.T., Erdman, K.A., \& Burke, L.M. (2016). American college of sports medicine joint position statement. Nutrition and athletic performance. Medicine \& Science in Sports \& Exercise, 48(3), 543-568. PubMed doi:10.1249/MSS.0000000000000852

Timbo, B.B., Ross, M.P., McCarthy, P.V., \& Lin, C.T. (2006). Dietary supplements in a national survey: Prevalence of use and reports of adverse events. The Journal of the American Dietetic Association, 106(12), 1966-1974. PubMed doi:10.1016/j.jada.2006.09.002

Trakman, G.L., Forsyth, A., Devlin, B.L., \& Belski, R. (2016). A systematic review of athletes' and coaches' nutrition knowledge and reflections on the quality of current nutrition knowledge measures. Nutrients, 8(9), pii: 570. PubMed doi:10.3390/nu8090570

Tscholl, P., Alonso, J.M., Dollé, G., Junge, A., \& Dvorak, J. (2010). The use of drugs and nutritional supplements in top-level track and field athletes. American Journal of Sports Medicine, 38(1), 133-140. PubMed doi:10.1177/0363546509344071

Tscholl, P., Junge, A., \& Dvorak, J. (2008). The use of medication and nutritional supplements during FIFA World Cups 2002 and 2006. The British Journal of Sports Medicine, 42(9), 725-730. PubMed doi: 10.1136/bjsm.2007.045187

Tsitsimpikou, C., Tsiokanos, A., Tsarouhas, K., Schamasch, P., Fitch, K.D., Valasiadis, D., \& Jamurtas, A. (2009). Medication use by athletes at the Athens 2004 summer Olympic games. Clinical Journal of Sport Medicine, 19(1), 33-38. PubMed doi:10.1097/JSM. 0b013e31818f169e

U.S. Food and Drug Administration (FDA). (2017). Dietary supplements. Retrieved from https://www.fda.gov/default.htm

Wardenaar, F.C., Ceelen, I.J., Van Dijk, J.W., Hangelbroek, R.W., Van Roy, L., Van der Pouw, B., . . . Witkamp, R.F. (2017). Nutritional supplement use by Dutch elite and sub-elite athletes: Does receiving dietary counseling make a difference? International Journal of Sport Nutrition and Exercise Metabolism, 27(1), 32-42. PubMed doi: 10.1123/ijsnem.2016-0157

Wiens, K., Erdman, K.A., Stadnyk, M., \& Parnell, J.A. (2014). Dietary supplement usage, motivation, and education in young, Canadian athletes. International Journal of Sport Nutrition and Exercise Metabolism, 24(6), 613-622. PubMed doi:10.1123/ijsnem.20130087 